\title{
Water Accounting for sustainable water resources management - role of hydrological modelling
}

\author{
$\underline{\text { Dushmanta Dutta }}^{\mathrm{a}}$, Shaun Kima ${ }^{\mathrm{a}}$ Jai Vaze ${ }^{\mathrm{a}}$, Justin Hughes ${ }^{\mathrm{a}}$ and Ang Yang \\ ${ }^{a}$ CSIRO Land and Water, Canberra, ACT, Australia \\ Email: dushmanta.dutta@csiro.au
}

\begin{abstract}
With increasing competition for finite and often scarce water resources, water information is critical for the water reform process. Water accounting, a systematic approach of organising and presenting water information relating to the physical volumes of water and how water resources are being used, provides a unique tool for integrated water resources management as well as for economic analysis of water issues. Due to limitation of available data and information at suitable spatial and temporal resolutions, it is difficult to produce water accounts in a consistent and systematic way in most of the river basins around the world. Hydrological models, if designed and implemented appropriately, can play a significant role in producing consistent and standardised water accounts complementing observed data and information. CSIRO and the Bureau of Meteorology of Australia have developed a hydrological river system model called "AWRA-R" for producing Australia's national water accounts. AWRA-R includes all the key hydrological processes and anthropogenic water utilisation that are required for producing different fluxes and stores for water accounting. The model is flexible enough to be able to use all available data sources (when modelling data rich and data limited regions) to provide nationally consistent and robust estimates. This paper describes the AWRA-R model and its calibration, validation, and application in the Murray-Darling Basin, Australia for producing various fluxes and stores required for water accounting in the basin.
\end{abstract}

Keywords: $\quad$ AWRA, water resources assessment, landscape modelling, river system modelling, hydrological modelling 
Dutta et al., Water Accounting for sustainable water resources management - role of hydrological modelling

\section{INTRODUCTION}

Water information is a critical underpinning of the water reform process both on which to base decisions and against which to measure progress. Water accounting is a systematic approach of organising and presenting water information relating to the physical volumes of water and how water resources are being used. It provides a unique tool for integrated water resources management as well as for economic analysis of water issues. The concept of water accounting is relatively new and it gained traction with water managers in the 1990s due to growing importance of sustainable management of water resources under increased and competing demands from multiple stakeholders. A water-accounting procedure from an irrigation perspective was introduced by Molden (1997) to better understand the impacts of irrigation interventions at a basin scale (Molden and Sakthivadivel, 1999). Peranginangin et al. (2004) adapted this procedure to account for groundwater and surface water components separately. In Australia, information on water resources has been compiled since the mid-1960s (Vardon et al., 2007). The ABS water Accounts (ABS 2000, 2004a) contained supply and use tables that tracked the extraction of water from the 'environment' through to consumptive use, regulated discharges to the environment and reuse. In these reports, data were consolidated from difference sources and there was no standards-based national approach to water resources reporting. The Council of Australian Government (COAG) played a pivotal role in the development of water policy in Australia. In 2004, COAG signed an intergovernmental agreement on a National Water Initiative (COAG, 2004), which mandated water accounting at the national level. Through the Water Act 2007, the Bureau of Meteorology was given the statutory responsibility for compiling and delivering comprehensive water information across Australia (BoM, $2012 \mathrm{a} \& \mathrm{~b})$. One of the legislative responsibilities of the Bureau was to produce national water accounts, which contains comprehensive and standardised information about the management of Australia's water resources. For producing the national water accounts, the Bureau required a river system modelling tool that quantifies water flux and storage terms using a combination of data sets. The system needed to be applicable across the continent and it should be flexible enough to be able to use all the available data sources (when modelling data rich and data limited regions) to provide nationally consistent and robust estimates.

The BoM and CSIRO established Water Information Research and Development Alliance in 2008 to collaborate on research activities in the field of water information (BoM \& CSIRO, 2013). As part of this alliance, a continental scale modelling system representing the Australian terrestrial water cycle, called Australian Water Resource Assessment (AWRA), was built and operationalised at the BoM for producing Australia's national water assessments and water accounts (Vaze et al., 2013). The AWRA river (AWRA-R) is the river system component of the AWRA system, which is a conceptual hydrological model that includes key hydrological processes and anthropogenic water utlisation that are required to simulate various fluxes and stores associated with river systems in both unregulated and regulated systems. The core objective of the model is to support the production of the national water accounts (NWA) by the BoM.

This paper describes the AWRA-R model and its calibration and validation and application in the MurrayDarling Basin, Australia for producing various fluxes and stores required for water accounting in the basin. The paper is structured as follows. AWRA-R model is described in Section 2. A brief description of the study area is then provided and data collation process is explained in Section 3. Section 4 presents the summary of the calibration and validation of the model in the MDB. The fluxes and stores simulated by the model are presented in Section 5. The conclusions from the study are presented in Section 6.

\section{AWRA-R MODEL}

The AWRA-R model has been designed using a node-link concept (Welsh et al., 2013; Dutta et al., 2013a), where a river system is schematised into a simplified river network using a node-link structure. The river network begins and ends with a node, and all nodes are interconnected by links. A link is used for transfer of flow between two nodes with routing and transformation. Runoff from gauged or ungauged tributaries or local contributing area between two nodes is fed into the connecting link as an inflow at the relevant location and all other physical processes (such as diversions, groundwater fluxes, overbank flow) occurring between the two nodes are incorporated in the link. The runoff from local flow contributing area to an AWRA-R link or reach is obtained from AWRA Landscape model (AWRA-L, Vaze et al., 2013).

The current version of the AWRA-R model (version 5.0) consists: i) Streamflow routing, ii) Local ungauged runoff, iii) Storage contribution modelling, iv) Irrigation modelling, v) Urban water use, vi) Water use for stock and domestic, vii) Rainfall to, and evaporation from river, viii) Anabranch flow, ix) Floodplain inundation modeling, and x) River and groundwater interaction modeling components. Figure 1 shows a conceptual diagram of a river reach (in a residual catchment) with different components of the model. In an AWRA-R simulation of a reach, all upstream inflows are routed first and then, local inflows are added and losses are 
Dutta et al., Water Accounting for sustainable water resources management - role of hydrological modelling

subtracted to calculate the outflow at the end of the reach. The general form of water balance for a reach (with routed upstream flow) for AWRA-R v5.0 can be described as follows:

$$
\widehat{Q_{d} / s}=\left(Q_{u / s}\right)_{\text {rout }}+Q_{r}+Q_{s}-Q_{d}+Q_{i r r}-Q_{u}-Q_{s d}+Q_{p}-Q_{e}-Q_{a}-Q_{f p}+Q_{f p r}-Q_{g w}
$$

Where, $\widehat{Q_{d / s}}=$ simulated flow at the downstream gauge, $Q_{u / s}=$ concurrent flow at the upstream gauges (including gauged tributaries), $\left(Q_{u / s}\right)_{\text {rout }}=$ upstream inflow following routing, $Q_{r}=$ runoff locally generated from the local ungauged catchment, $Q_{s}=$ contribution from any storages including rainfall on storage area, evaporation from storage area and change in storage volume, $Q_{d}=$ loss due to irrigation diversion modelled with a separate irrigation model (Hughes et al., 2014), $Q_{i r r}=$ total return flow from irrigated area, $Q_{u}=$ net loss due to urban diversion, $Q_{s d}=$ rural water use (other than irrigation) for stock and domestic, $Q_{p}=$ the flux to the river store due to rainfall, $Q_{e}=$ the flux from the river due to evaporation, $Q_{a}=$ the flow diverted to anabranches, $Q_{f p}=$ overbank flow to floodplain, $Q_{f p r}=$ return flow from floodplain, $Q_{g w}=$ the flux from river to groundwater.

The governing equations of each of the model components and input data and outputs are detailed in Dutta el al. (2015). AWRA-R model has 8 calibration parameters for every modelled reach: Lag, $K, x, O T, F R, M_{1}, M_{2}$, $S F$. The first three parameters ( $\operatorname{Lag}, K, x)$ are associated with flow routing from upstream to downstream using Muskingum routing scheme. Parameters $O T$ (overbank flow threshold) and $F R$ (floodplain return flow coefficient) are associated with overbank flow modelling component (Dutta et al., 2013). $M_{1}$ and $M_{2}$ are two parameters of MONOD function, which is used to constraint groundwater recharge estimate from a river reach. The final parameter $(S F)$ is a scaling factor used for scaling the ungauged runoff obtained from AWRA-L model. Two autocalibration approaches, namely, reachby-reach and system calibration, have been designed for optimisation of reach-level model parameters using user-defined optimisers and objective functions. In the reach-by-reach calibration approach, the model parameters are optimised at a reachlevel in a cascading manner from upstream to downstream reaches using a local objective function. Whereas, the system calibration approach is designed to optimise all model parameters for a region (consisting of multiple reaches) simultaneously using a system-wide global objective function (Hughes et al., 2015).

\section{STUDY AREA}

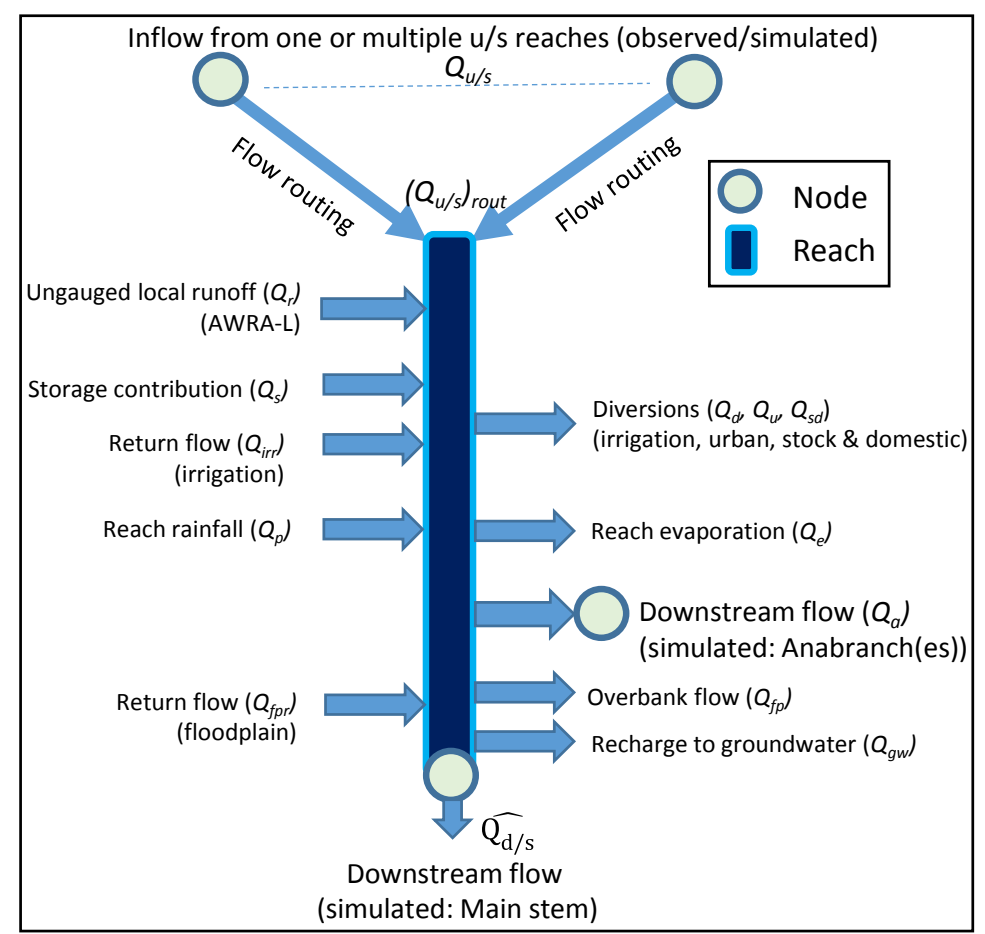

Figure 1. The conceptual diagram of AWRA-R v5.0 reach with different modelling components.

The Murray-Darling Basin (MDB) is one of the largest basin in Australia with an area of about 1 million $\mathrm{km}^{2}$. The MDB river system is a highly complex and mostly regulated system covering four states (Queensland, New South Wales (NSW), Victoria and South Australia) and one territory (ACT). For the purpose of AWRA$\mathrm{R}$ modelling, the entire MDB was divided into 18 contiguous regions based on the divisions used in the MurrayDarling Basin Sustainable Yields Project (CSIRO, 2008). These regions, namely Paroo, Warrego, CondamineBalonne, Moonie, Border Rivers, Gwydir, Namoi, Macquarie-Castlereagh, Barwon-Darling, Lachlan, Murrumbidgee, Murray, Ovens, Goulburn-Broken, Campaspe, Loddon-Avoca, Wimmera and Eastern Mount Lofty Ranges, are primarily the drainage basins of the Murray and the Darling rivers and their tributaries (Figure 2). Within the MDB, the irrigated areas are mainly located within Condamine-Balonne, Border Rivers, Gwydir, Namoi, Barwon Darling, Macquarie Castlereagh, Lachlan, Murrumbidgee, Murray, Goulburn-Broken and Loddon-Avoca. The AWRA-R v5.0 model in the MDB region included a total of 485 gauges and 33 large and medium size storages. The data collation and model setup are elaborated in Dutta et al. (2015). 
Dutta et al., Water Accounting for sustainable water resources management - role of hydrological modelling

\section{CALIBRATION AND VALIDATION}

Based on the lengths and quality of the streamflow data at the selected gauges and climatic variability in the MDB region, the period of 1970-1991, covering both wet and dry climate, was selected for calibrating AWRAR v5.0 model. A more recent period of 1992-2014 was selected for validating the model. The summary statistics (daily NSE and absolute bias in \%) of the model performance during the calibration (reach-byreach) and validation periods are presented in Figure 3. In the calibration, the model performed reasonably well in the MDB with the median daily NSE of 0.64 as shown in Figure 3a. Within the $\mathrm{MDB}$, the performance varied from one sub-region to another with daily NSE ranging between 0.45 0.85 . The median values of annual bias during the calibration were very low $(<7 \%)$ for all subregions within MDB as shown in Figure 3c. The calibrated model performed very well under the validation mode with the median daily NSE of 0.68 for the MDB. Within the MDB, the daily median NSE varied between 0.43-0.90 as shown in Figure 3 b. This was consistent with the results under the calibration mode. In the validation, the median value of annual bias was $12 \%$ for the MDB (Figure $3 \mathrm{~d})$ with a variation between $1-28 \%$ between different sub-regions.

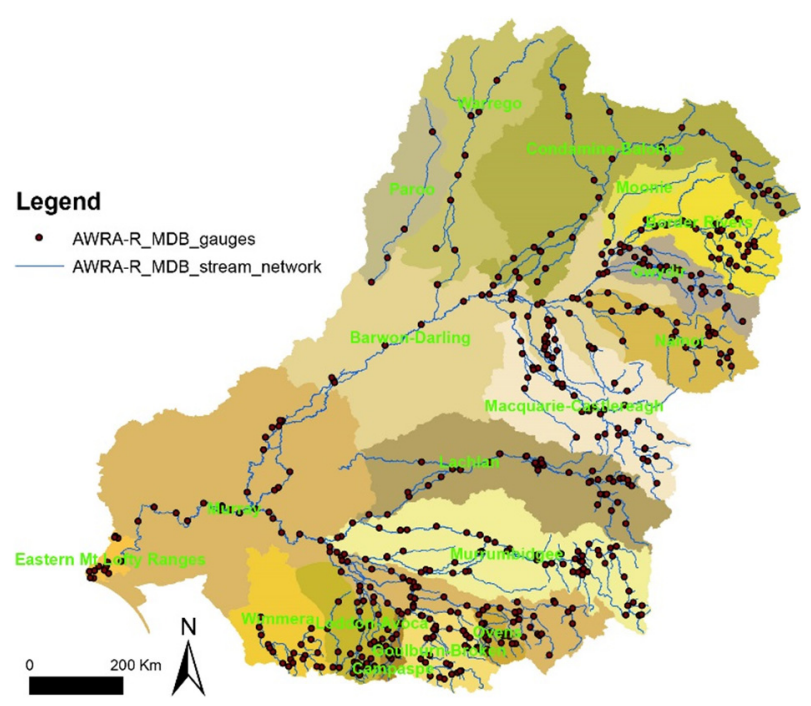

Figure 2. AWRA-R v5.0 node-link network for the Murray-Darling Basin.

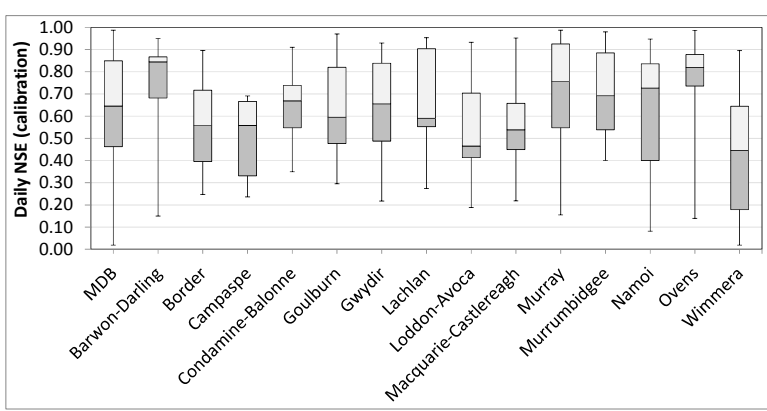

a) daily NSE: calibration

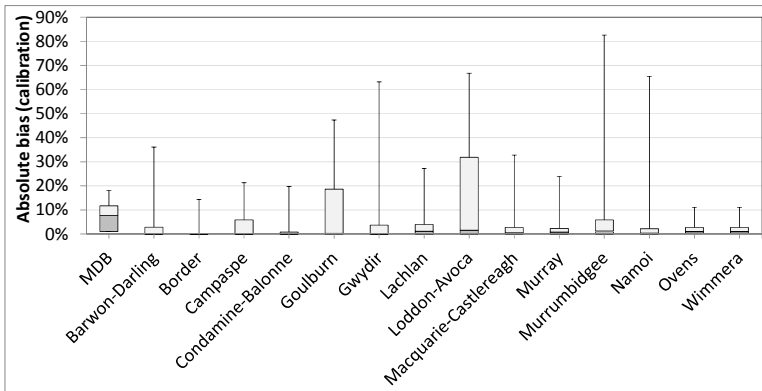

c) bias: calibration

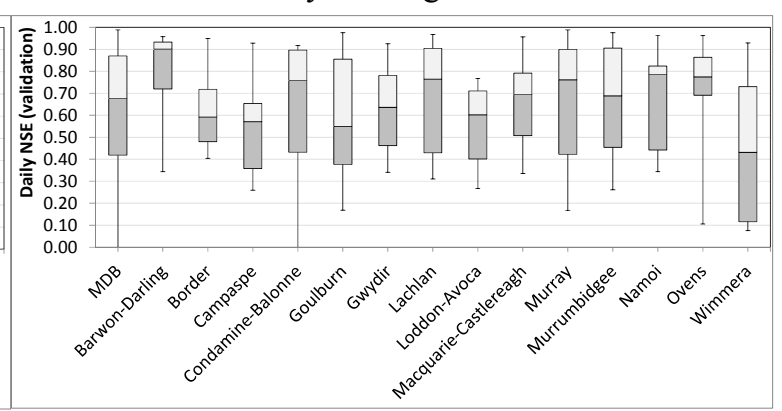

b) daily NSE: validation

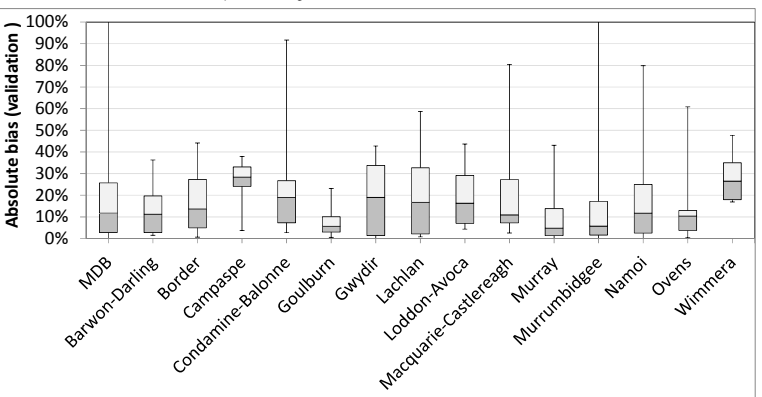

d) bias: validation

Figure 3. Summary statistics of the model performance for different regions and MDB sub-regions during the calibration (period: 1970-1991) and validation (1992- 2014) of AWRA-R v5.0 model.

\section{SIMULATION OF FLUXES AND STORES FOR WATER ACCOUNTING}

The calibrated model was used to simulate the fluxes and stores associated with different components of the Murray-Darling river system. Figure 4 shows an example of daily time series of the simulated irrigated area and the fluxes such as diversion, surface runoff, groundwater pumping and groundwater recharge associated with irrigation along a reach in the Barwon River for the period of 1970-2010. Similar fluxes and stores were produced for all 60 modelled reaches within the MDB with irrigation diversions. This period included the millennium drought, which had a large effect on irrigation in the MDB. As can be seen from Figure 4, the 
Dutta et al., Water Accounting for sustainable water resources management - role of hydrological modelling

annual variation of irrigated area was very high with large reductions in the irrigated area and associated diversions in the later years of the decadal drought (from 2006 to 2009).

Figure 5 shows an example of daily time series of floodplain fluxes including overbank flow from the river reach to floodplain, net loss from floodplain due to evaporation and groundwater recharge, and return flow from floodplain and floodplain storage volume for a floodplain reach in the Murrumbidgee from 1975-2012. There were only a limited number of overbank flow events along this reach, most of which occurred between 1975-1992. Overbank flow again started occurring along this reach after the millennium drought at the end of 2010. Similar time series of floodplain fluxes and stores were produced by the AWRA-R model for all 166 reaches located within the floodplains in the MDB.

The AWRA-R model also produces a number of other fluxes and stores at a reach level and a daily time step for all the modelled reaches. A complete list of the simulated daily fluxes and stores are shown in Table 1. The BoM produces water accounts annually for a number of major river basins across Australia (http://www.bom.gov.au/water/nwa/). Due to
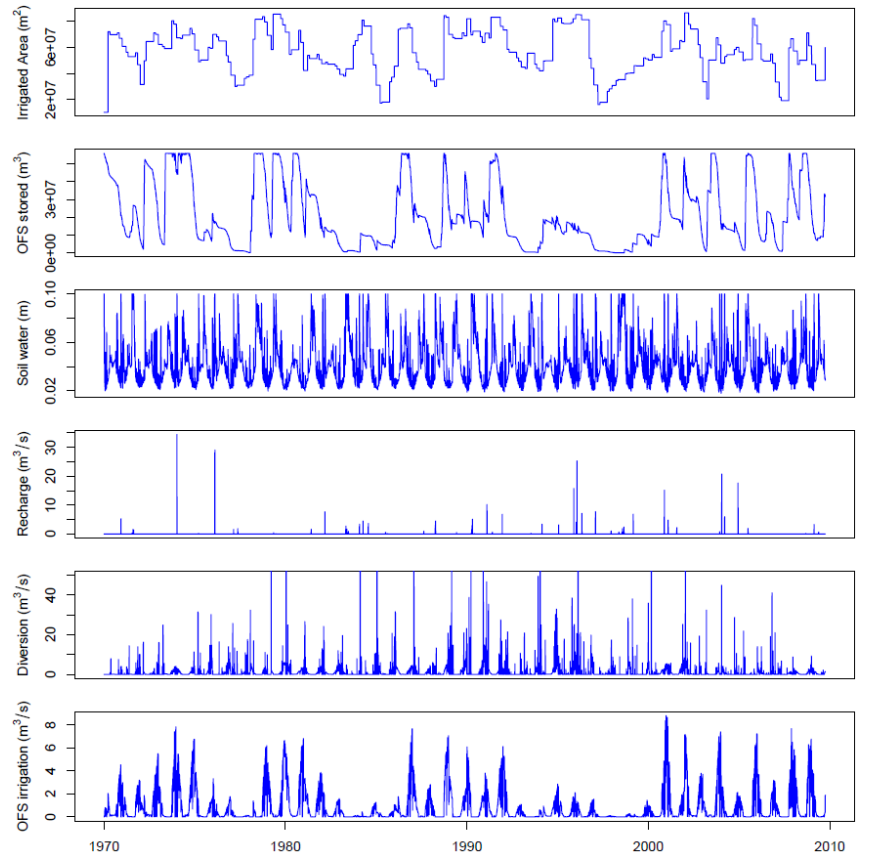

Figure 4. Simulated fluxes and stores related to irrigated area (Barwon at Mungindi).

non-availability of observed data for most of the fluxes and stores required for producing various line items for water accounts, the simulated outputs from the calibrated AWRA-R model (as shown in Table 1), which are consistent and reliable, are necessary for comprehensive water accounting.

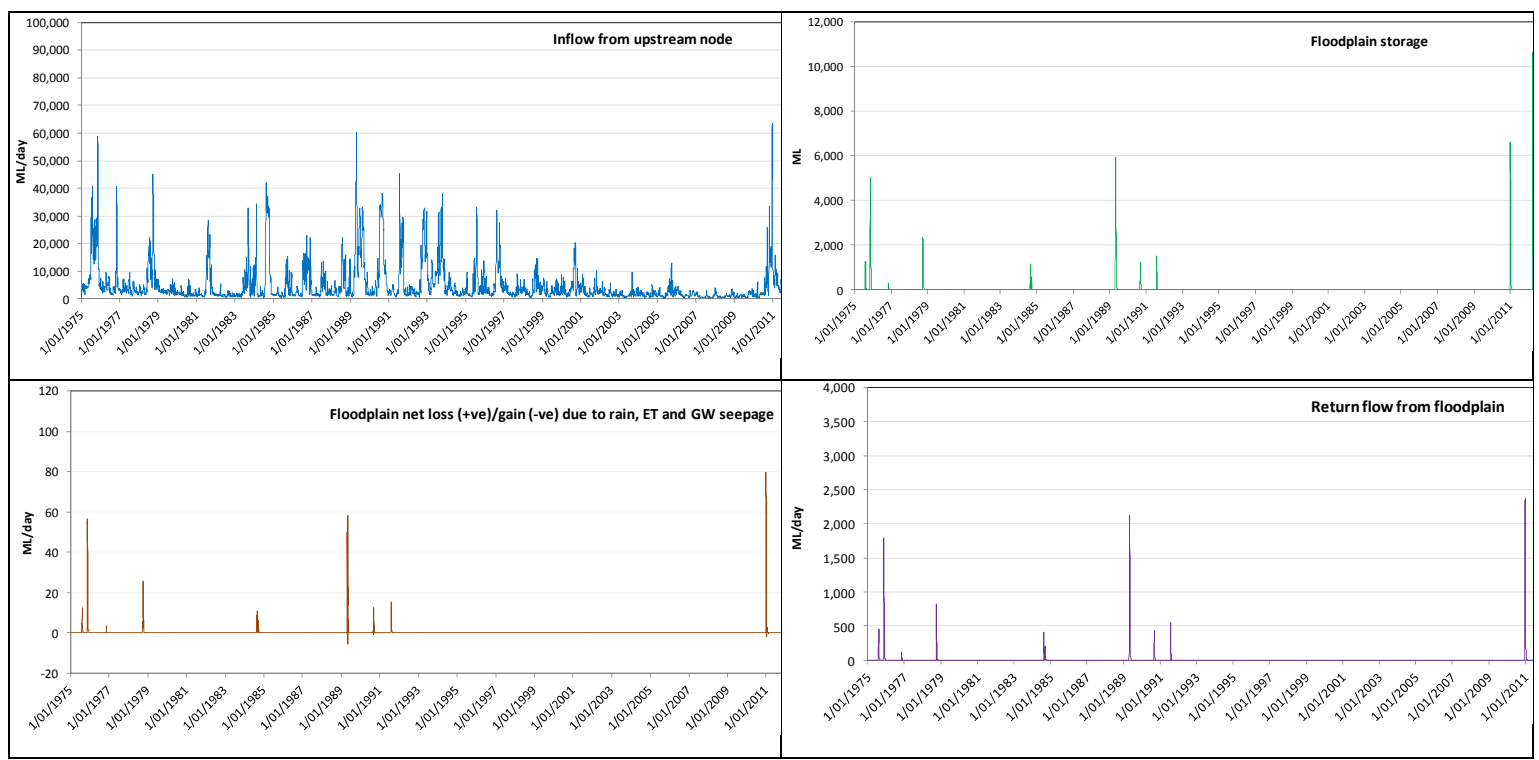

Figure 5. AWRA-R simulated floodplain fluxes and stores for reach between Hay and d/s of Hay weir in Murrumbidgee.

The daily outputs from AWRA-R model can be easily aggregated to produce the overview at a basin or regional scale as well as for different periods such as monthly and annual. Figure 6 shows an example of the annual average values of the major fluxes (in GL) associated with the modelled river reaches in the Gwydir catchment within the MDB covering the entire period of modelling for both headwater and non-headwater catchments. In the headwater catchments, overbank flow and floodplain fluxes are not calculated. 
Dutta et al., Water Accounting for sustainable water resources management - role of hydrological modelling

Table 1. List of the simulated fluxes and stores at a reach level by AWRA-R model.

\begin{tabular}{|l|}
\hline Simulated Fluxes and stores at river reach scale \\
\hline Outflow \\
\hline Overbank flow \\
\hline Floodplain volume \\
\hline Floodplain area \\
\hline Floodplain return flow \\
\hline River rainfall flux \\
\hline River evaporation flux \\
\hline Floodplain rainfall flux \\
\hline Floodplain evaporation flux \\
\hline Floodplain groundwater loss \\
\hline River groundwater loss \\
\hline Anabranch loss \\
\hline Reservoir rainfall flux \\
\hline Reservoir evaporation flux \\
\hline Reservoir contribution \\
\hline River volume \\
\hline Floodplain groundwater max change storage \\
\hline Floodplain groundwater outflow \\
\hline Floodplain groundwater max potential infiltration \\
\hline River groundwater max change storage \\
\hline River groundwater outflow \\
\hline Max groundwater infiltration from river \\
\hline Irrigation diversion \\
\hline Irrigated area \\
\hline OFS stored volume \\
\hline Soil water \\
\hline Recharge from irrigated area \\
\hline OFS irrigation \\
\hline
\end{tabular}

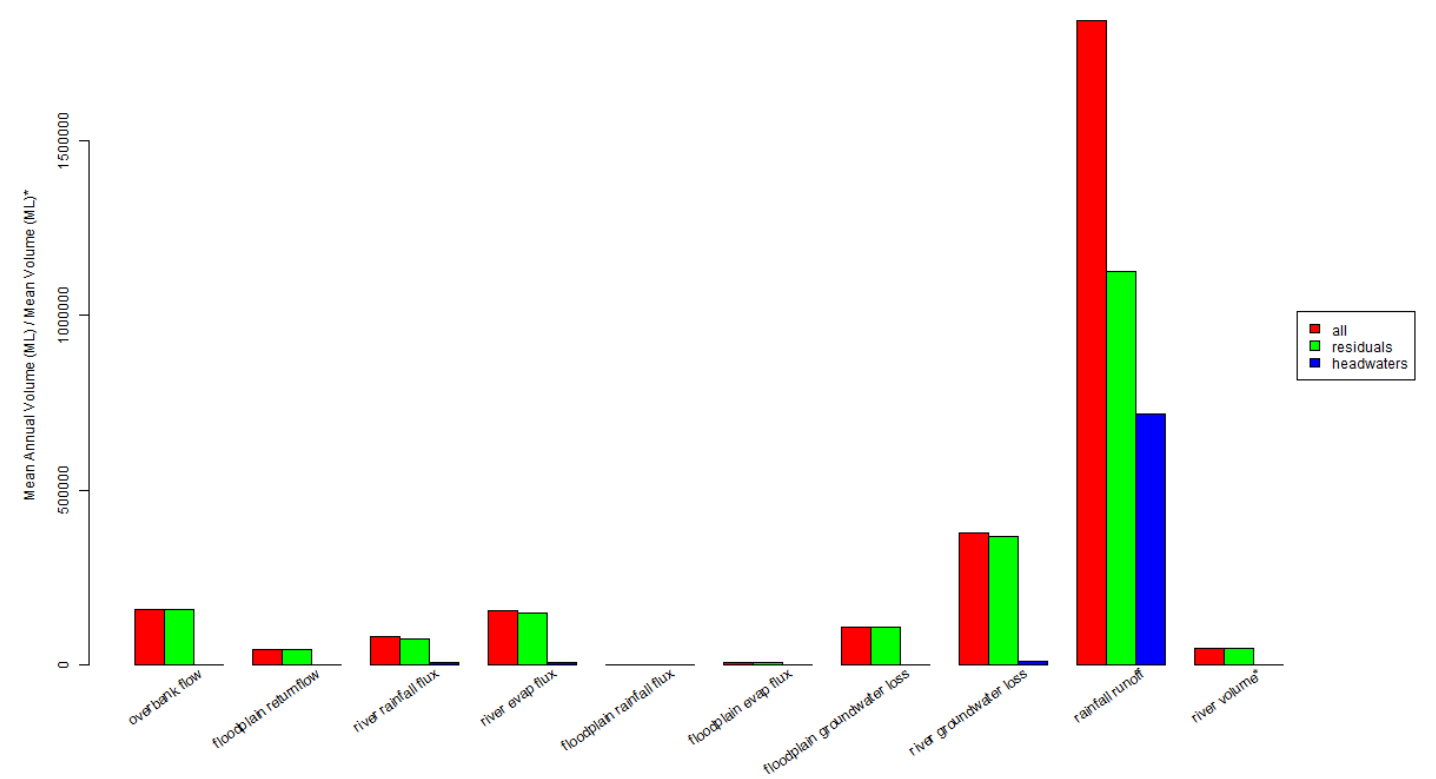

Figure 6. Annual average values of major fluxes (in GL) for Gwydir catchment.

\section{CONCLUSIONS}

The paper has introduced the AWRA-R model, which has been designed to produce various fluxes and stores associated with a river system for the purpose of water accounting. The results of the reach-by-reach calibration 
Dutta et al., Water Accounting for sustainable water resources management - role of hydrological modelling

of the model in the MDB show highly satisfactory performance of the model in the MDB with median daily NSE of 0.74 and median annual bias of less than $3 \%$ for the period of calibration. AWRA-R produces quantitative estimates of various stores and fluxes associated with both regulated and unregulated systems at a daily time step. The ability of the model to produce such comprehensive estimates of water stores and fluxes at high temporal and spatial resolutions for large basins is a remarkable improvement over the existing water accounting tools and large scale hydrological models. This quantitative information provides a detailed understanding of major components of water balances at a reach level for water resources analyses and reporting purposes. The AWRA-R model outputs underpin the first set of consistent water accounts across continental Australia and it will be used by the BoM to update these accounts every year in the future.

\section{ACKNOWLEDGEMENT}

This work is carried out in CSIRO Land and Water and is funded by the WIRADA project.

\section{REFERENCES}

ABS (Australian Bureau of Statistics), 2000. Water Account for Australia, 1993-94 to 1996-97. ABS Cat. no. 4610.0 .

ABS (Australian Bureau of Statistics), 2004. Water Account, Australia 2000-01. ABS Cat. no. 4610.0. Summary at: http://www.abs.gov.au/ausstats/ABS@.nsf/mf/4610.0.

BoM (2012a). Australian Water Accounting Standard 1: Preparation and Presentation of General Purpose Water Accounting Reports (AWAS 1), The Bureau of Meteorology, Australia.

At: http://www.bom.gov.au/water/standards/documents/awas1_v1.0.pdf

BoM (2012b): Illustrative Water Accounting Reports for Australian Water Accounting Standard 1: Preparation and Presentation of General Purpose Water Accounting Reports (AWAS 1), The Bureau of Meteorology.

BoM \& CSIRO (2013). Water Information Research and Development Alliance ANNUAL REPORT 201213, the Bureau of Meteorology and CSIRO, 28p.

COAG (2004). Intergovernmental Agreement on a National Water Initiative, Council of Australian Governments, at: http://www.coag.gov.au/meetings/250604/index.htm\#water initiative.

CSIRO (2008). Water availability in the Murray-Darling Basin. A report to the Australian Government from the CSIRO Murray-Darling Basin Sustainable Yields Project. CSIRO, Australia.

Dutta, D., K. Wilson, W. Welsh, D. Nicholls, S. Kim, L. Cetin (2013a). A New Modelling System for River Operations with a Case Study from the Goulburn River, Australia, Journal of Environmental Management, 121:13-28.

Dutta D, Teng J, Vaze J, Lerat J, Hughes J and Kim S (2013b). Development and implementation of AWRAR flood inundation module. CSIRO Water for a Healthy Country Flagship, Australia. 69 pages.

Dutta D, Kim S, Hughes J, Vaze J, Yang A (2015) AWRA-R v5.0 Technical Report. CSIRO, 100 pages.

Hughes J, Dutta D, Yang A, Marvanek S, Vaze J, Mainuddin M (2014). Improvement of AWRA-R Irrigation Model and its Applications in the Murray-Darling Basin, CSIRO, Australia, 44 pages.

Hughes J, Kim S, Yang A, Dutta D, Vaze J (2015). Whole of system calibration of river models: Weighting functions and their effect on individual gauge and system performance, MODSIM 2015.

Molden D (1997). Accounting for Water Use and Productivity, SWIM Paper 1, International Water Management Institute, Colombo, Sri Lanka.

Molden D, Sakthivadivel R (1999). Water accounting to assess use and productivity of water. Water Resour. Dev., 15:55-71.

Peranginangin N, Sakthivadivel R, Scott NR, Kendy E, Steenhuis TS (2004). Water accounting for conjunctive groundwater/surface water management: case of the Singkarak-Ombilin River basin, Indonesia, Journal of Hydrology, 292:1-22.

Vardon M, Lenzen M, Peevor S, Creaser M (2007). Water accounting in Australia, Ecological Economics, 61: 650-659.

Vaze J, Viney N, Stenson M, Renzullo L, Van Dijk A, Dutta D, Crosbie R, Lerat J, Penton D, Vleeshouwer J, Peeters L, Teng J, Kim S, Hughes J, Dawes W, Zhang Y, Leighton B, Perraud JM, Joehnk K, Yang A, Wang B, Frost A, Elmahdi A, Smith A, Daamen C (2013). The Australian Water Resource Assessment System (AWRA). Proceedings of the MODSIM2013, Adelaide, Australia, December 2013, 3015-3021.

Welsh WD, Vaze J, Dutta D, Rassam D, Rahman JM, Jolly ID, Wallbrink P, Podger GM, Bethune M, Hardy MJ, Teng J, Lerat J (2013). An integrated modelling framework for regulated river systems, Environmental Modelling \& Software, 39:81-102. 